\title{
CONSIDERATIONS ON THE APPLICATION OF AHP/ANP METHODOLOGIES TO DECISIONS CONCERNING A RAILWAY INFRASTRUCTURE
}

\author{
Giovanni Longo \\ Department of Civil and Environmental Engineering \\ University of Trieste, Italy \\ E-mail: longo@dica.units.it \\ Elio Padoano* \\ Department of Mechanical Engineering \\ University of Trieste, Italy \\ E-mail: padoano@units.it \\ Paolo Rosato \\ Department of Civil and Environmental Engineering \\ University of Trieste, Italy \\ E-mail: rosato@dica.units.it \\ Stefano Strami \\ Department of Civil and Environmental Engineering \\ University of Trieste, Italy \\ E-mail: stefano.strami@libero.it
}

\begin{abstract}
The objective of the paper is to present the results of the application of AHP and ANP to support a strategic decision in the field of railway transportation in Italy. The problem issue involves various actors in the process of choosing the most promising alternative among four different infrastructural projects. At a first stage the problem was analyzed and modeled following the AHP methodology: a hierarchy was constructed and relative priorities were obtained by means of a panel of experts. During the assessment process, some considerations arose about the complexity of the problem and, as a consequence, about the effectiveness of the AHP basic hypotheses. This led to a further stage of the assessment process. The aim of this new phase was to explicitly include within the process interactions between different clusters of the decision model through the ANP approach. The structure of this second model enriched the previous hierarchy by considering the most evident feed-back relations, so the ANP data were basically the same as in AHP. Finally, the same study case was modeled as an ANP network with the BOCR scheme. This final stage required a very profound (and time-consuming) comprehension of the matter both by the analysts and by the actors involved in the process. The contribution of this work to the discussion, is to draw a comparison between the AHP and the ANP paradigms for decision aiding and to propose some considerations on their application in a specific problem situation.
\end{abstract}

Keywords: ANP, decision aid, railway, transportation, case study

* Corresponding author 


\section{Introduction}

Planning and implementation of transportation infrastructures and services are results of complex decision processes that usually involve numerous stakeholders and interest groups. Public and private decision makers have diverse goals and they can perceive different problem issues or opportunities. The same object of discussion, for example a railway link between two nodes, may have different meanings and it may be appreciated from several points of view. The final course of action, such as a plan or a project, is then the result of a process in which several criteria are taken into account, explicitly or implicitly.

In order to provide support in such processes, a decision facilitator (analyst) should employ methods and tools both to describe the problem situation, and in particular the roles of different actors, and to suggest the most efficient solution for the specific problem. Different methodologies have been proposed to support decision makers and analysts in transportation decision processes. Multiple criteria decision analysis - MCDA - approaches are widely used because they can consider issues that cannot be easily expressed with economic (monetary) measures. For example, an interesting comparison between the output of cost-benefit analysis (CBA) and MCDA is presented in Tudela, Akiki, and Cisternas (2006) with reference to a transportation case study, while Tsamboulas and Mikroudis (2000) propose a combination of the two approaches in order to evaluate the environmental impacts and costs of transport alternatives.

The Analytic Hierarchy Process (AHP) has been extensively used in decision problems related to transportation infrastructures (see, for example, Rabbani and Rabbani, 1996; Yedla and Shrestha 2003; Gerçek, Karpak, and Kilinçaslan, 2004). The success of this methodology is partly due to its relative simplicity of use, but it is almost certainly related to its effectiveness in supporting the three main phases of a decision process: problem structuring, evaluation of criteria and/or alternative performances and analysis-synthesis (Forman and Gass, 2001; De Brucker, Verbeke, and Macharis, 2004). In addition, AHP is able to deal with imprecise and subjective judgments that characterize decisions that can affect several groups or stakeholders on a long time period.

More recently, Saaty proposed the Analytic Network Process (ANP) that can be considered as a generalization of AHP (Saaty, 1996; Saaty, 2005). This methodology makes it possible to model a decision problem taking into account the influences that may exist among its different aspects. In particular, it allows to take into account an aspect that has been frequently observed in real situations: the dependence of the priorities derived for the upper level elements (e. g. criteria) from the characteristics of the lower level elements (e. g. alternatives). Therefore ANP represents the general model of which AHP is a particular case. In the transportation sector ANP is not as widespread as AHP, however there are studies that provide interesting methodological and operational insights (Meade and Sarkis, 1998; Shang, Tjader, and Ding, 2004; Piantanakulchai, 2005; Wey and Wu, 2007). The approach needs to be tested in different kind of situations that show systemic relations between elements that cannot be tackled by other methods. The quantity and quality of the information processed for building and exploiting the model should also be analyzed to assess the usefulness in real world applications.

In this context, the main objective of the paper is to offer a contribution to the discussion, with reference to a case study that refers to the localization of a new railway line within a metropolitan area in Italy. This railway should be used mainly by freight traffic as a shunt of the main railway node, where congestion is present due to passenger traffic. This problem presents transportation, environmental and political aspects and many decision makers are involved. There are four project alternatives that were proposed by different subjects representing various stakeholders.

In a preceding study (Longo, Padoano, Rosato and Strami, 2008) the decision problem was modeled by means of a hierarchy and of a simple network, and the main findings were presented. In the present paper the same study case was modeled as an ANP network with the BOCR scheme. This final stage 
required a very profound (and time-consuming) comprehension of the matter both by the analysts and by the actors involved in the process.

The contribution of this work to the discussion, is to draw a comparison between the AHP and the ANP paradigms for decision aiding and to propose some considerations on their application in a specific problem situation.

\section{Some issues regarding Analytic Hierarchy Process and Analytic Network Process}

The problem situation was analyzed by considering different modeling structures. Each structure was based on the same decision process setting that included four active stakeholders and four project alternatives. The first structure was based on a hierarchy while the others were built by following ANP approaches.

In the Analytic Hierarchy Process the decision problem is structured as a hierarchy of elements in which the main goal of the problem is represented by the top element and the alternative actions or decisions are the bottom elements. The main goal is progressively disaggregated into criteria and subcriteria at different levels of the hierarchy. The aim is to represent the factors that can influence the decision from the more general (aggregate) ones to the more specific (Saaty, 2008). The second main step consists of the comparison of couples of elements of the same level with respect to an element of the immediately above level: the aim is to assess (relative) priorities, in terms of preference or importance, to lower level elements with respect to the higher level element taken into consideration. The hierarchy framework assumes that the priorities of the items in a higher level do not depend on the priorities of the items of lower levels. This implies a top-down orientation of the model structure. This structure has a straightforward representational potential and it makes it possible to perform a thorough analysis of the different aspects of the problem, identifying the elements of the hierarchy, their attributes and relations.

As previously noted, the Analytic Network Process is a generalization of AHP. A network framework is designed to deal with situations that are characterized by dependence and feedback among elements of different clusters (outer dependencies) or of the same group (inner dependencies). The resulting network does not need to show a main stream of influences like the hierarchical approach. In a network it is possible to describe more accurately and with greater flexibility the problem setting by means of the mutual relations of the elements. In particular, several authors observed that the characteristics of the available solutions can influence the priorities of criteria (see, for example, Simon, 1957; Saaty, 1996; Mingers and Rosenhead, 2001). The priority of two criteria of the same group (cluster) can depend upon their importance with respect to an element of the same "type" (a criterion) that is part of another cluster. Such priority can also be affected by the alternatives when the criteria can be seen as attributes of the alternatives, and therefore their global importance, in that specific problem situation, depends upon the levels of attributes that are actually appreciated in the alternatives.

One of the possible implementations of the ANP framework provides for a single network of items of two orders of complexity (elements and clusters) connected by their dependence to one another. The existence and strength of relations are the results of a systemic analysis of the problem issue with specific reference to the main goal that assumes the role of a "control criterion" (Saaty, 1999). Elements have a simpler complexity and they are grouped in higher order clusters according to their common properties. Comparisons between elements of a cluster are performed with respect to each element to which they are connected, and comparisons between clusters are carried out in respect to each cluster they are linked to. The assessment of priorities is performed, in any case, by taking into consideration the main goal that controls the levels of interaction.

This kind of framework was employed for the problem under study: the main issues and the results obtained were exposed in the cited previous paper (Longo et al., 2008). In particular, it was 
underlined that the analysis of the problem had to be more detailed than the investigation that was required by the application of the hierarchical framework. However, such study brought a better comprehension of the problem issue and, in particular, in terms of the present meaning of the alternative solutions and how they influence the structure of preferences related to the specific situation.

In light of the results obtained by the application of ANP to the specific case study, it was decided to extend the analysis of the problem situation by introducing several control criteria articulated according to the four benefits, opportunities, costs and risks (BOCR) merits. The BOCR network represents an advanced framework to link the more general system of values of the actors involved in a complex decision to the specific attributes of alternative courses of action (Saaty, 2005).

The decision process under study was characterized by alternatives promoted by four key parties and these were in turn subjected to possible pressures coming from several stakeholders (groups of interest). Therefore, for each control criterion a network formed by three clusters (alternatives, key decision makers and stakeholders) was identified. This kind of modeling approach was proposed in other studies (Saaty, 2001; Shang, Tjader, and Ding, 2004; Piantanakulchai, 2005), and in the case here discussed made it possible to focus the influences that could rise among actors, groups and alternative solutions with respect to each control criterion. The case study and the BOCR network are presented in the following sections.

\section{The case study}

The case study refers to a new railway connection between the AV/AC line Turin-Milan and the Turin-Lyon border connection around the city of Turin. It has been defined more commonly "Gronda" and it should be dedicated specifically to freight traffic. The aim of this new line is to bring freight traffic outside the node except for traffic flows which have as origin / destination in Turin. The freight traffic which only transit through Turin could then select its path toward both the line actual TurinMilan or toward the new AV / AC Torino-Novara-Milano line of the AV / AC Torino-MilanoBologna-Firenze-Napoli System. The main purpose of this external railway connection is to make the itineraries of freight and passengers trains as independent as possible within the node in order to improve the general performances of the railway infrastructure in terms of capacity, regularity and reliability.

In this context, during the development of the project, many observations and suggestions arose from the involved local authorities, who proposed al least two alternative layouts in order to optimize or reduce the impacts of the original solution. These new solutions concern a meaningful segment of the new line and precisely the portion of line crossing the metropolitan area in Turin. The solutions are:

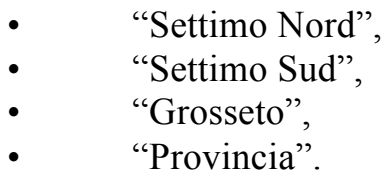

The solution "Settimo Nord", that was proposed by the Italian Railway Company and which lays near the Turin belt highway on the Northern side, presents two short tunnels in order to eliminate the interference with important highways. It is connected to the Turin-Milan lines near the town of Settimo, which lies outside the Turin node. "Settimo Sud" was proposed by the Italian Railway Company too and is really similar to the previous one but it is placed on the Southern side of the highway. The alternative "Grosseto" was proposed by the local municipality and is mainly characterized by the building of a long underground tunnel passing beneath the city centre. Eventually, the solution "Provincia" was proposed by the Province of Turin and aims at joining the new line to the existing railway node in Stura station which lies within the Turin node (although peripherally) in order to favour high-speed traveller transportation as well as freight traffic. 
These alternatives were analyzed in detail with respect to 49 parameters and an evaluation matrix with mainly quantitative indicators and with some qualitative judgments was assessed. The considered criteria are divided into the following sets:

- Costs;

- Transportation efficiency;

- $\quad$ Environmental impacts;

- $\quad$ Procedural aspects.

As for "Costs", the project costs are mainly considered. "Transportation efficiency" includes safety, especially within the tunnels, competitiveness as regards slot allocation and running efficiency expressed in term of capacity and reliability. As regards "Environmental impacts", they refer to natural, physical and urban resources and have been quantified through a GIS. Finally the "Procedural aspects" criterion allows taking into consideration the problems which would arise due to the modification of the original project and its new interferences on existing networks and services. These elements could lead to cost increase and mainly to longer realization times.

As a first step the AHP was applied. The hierarchy was defined according to the decision makers (DMs). Also the priorities were set according to each DM's point of view: comparisons were performed following a strict top-down approach. Priorities of the criteria of level 1 were assessed with respect to the main goal and the importance of sub-criteria was judged in respect to upper level criteria. In particular the most important criterion was "Environmental impacts"; "Transportation impacts", "Procedural impacts" and "Costs" follow. These weights show their effect on the final evaluation results that are shown in Figure 1. Each line reports graphically and numerically the priorities of an alternatives; "raw" values are results obtained in the matrix calculations, "normals" are same results normalized between 0 and 1 , and "ideals" are obtained from "normals" by dividing each value by the largest value in the column.

No reciprocal influence relationship nor feedback were implemented in this first step, this being a straight top-down AHP hierarchy. Once the comparisons had been performed and the subsequent priorities had been calculated for all the criteria in the hierarchy, the synthesis of the model represented quite a well-defined situation. Two of the alternatives ("Settimo Nord" and "Sud") performed decisively better than the other two.

\begin{tabular}{|l|c|c|c||c|}
\hline \multicolumn{1}{|c|}{ Name } & Graphic & Ideals & Normals & Raw \\
\hline \hline Grosseto & & 0.711548 & 0.208984 & 0.072564 \\
\hline \hline Provincia & & 0.716155 & 0.210337 & 0.073033 \\
\hline \hline Settimo Nord & & 1.000000 & 0.293703 & 0.101980 \\
\hline \hline Settimo Sud & & 0.977100 & 0.286977 & 0.099645 \\
\hline
\end{tabular}

Figure 1. AHP results and ranking (freight model).

As stated before, in a further stage of this work, a simple-network ANP structure was created, thus taking into account some important relationships of relative influence among nodes and clusters. This time, the criteria which contribute, with different weights, to the choice were grouped into three clusters: "Transportation efficiency", "Procedural aspects" and "Environment". These clusters corresponded to the clusters of the AHP hierarchy except as regards the cost criterion, which was included within the "Procedural aspects" group.

Bidirectional relations were created between each of the nine criteria and the alternatives; in fact, a more thorough analysis of the problem issue made it possible to interpret criteria in terms of attributes 
of the available solutions. This means that, on the one hand, the different alternatives had a rating with respect to each of the criteria and, on the other hand, the criteria had a different importance for each of the alternative options. The solution Grosseto, for instance, highlights the question of "Safety" more than the "Transportation efficiency"; the alternative Settimo Nord, instead, as it situates the line in a rural area, tends to make "Natural environment" crucial, rather than the "Historical patrimony".

As far as the criteria in clusters "Transportation efficiency" and "Procedural aspects" are concerned, their importance is influenced by the alternatives and also by other elements in the same cluster. For example, "Project restraints" and "Infrastructure interference" make "Costs" vary and similarly "Running efficiency", as well as "Safety", can modify "Competitiveness". Therefore the alternative Grosseto, being particularly crucial in "Safety", may result in a slightly lower rating in "Competitiveness" as well.

The ANP model confirmed the results obtained with the AHP scheme. Two solutions ("Settimo Nord" and "Settimo Sud") again seemed to perform definitely better than the remaining two. A first attempt to understand the reason for local authorities to promote apparently uninteresting alternatives was made modifying the priorities of criteria and alternatives considering a different point of view not only freight but also passenger transportation. Indeed, the new results for the "travellers" model highlighted a new situation. In this case, it was the alternative called "Grosseto" to draw the attention, followed by "Provincia".

The new modified ANP model, therefore, proved useful to remark this peculiarity of the case study. The next effort was to try to consider these different points of view (interest mainly in freight or passenger transportation) in a comprehensive structure by taking into consideration the BOCR merits. For this reason, the case study was analyzed by means of a new model. First of all, a simple top-level strategic hierarchy was created taking into account the four main objectives that lead to the final decision: Economic factors, Transportation, Territory and Strategic Project Management. The priorities of these four elements were assessed by pairwise comparisons with respect to the main goal: Territory resulted the most crucial matter (0.35), followed by Economic aspects (0.30). The control criteria were divided among four merit subnets: Benefits, Opportunities, Costs and Risks.

In order to make the new structure (BOCR) comparable with the two previous ones (AHP and simplenetwork ANP), each of the four merit categories was developed as a hierarchy, similar to the one used in the first AHP model, where all the control criteria (49) can be seen either as a short- (B) or longterm $(\mathrm{O})$ positive effect, or an immediate $(\mathrm{C})$ or future $(\mathrm{R})$ possible negative drawback. It was considered reasonable and useful to adopt for criteria the same priorities obtained with the first AHP scheme with respect to the main goal. For instance, the structure referring to Risks is reported in Figure 2. 


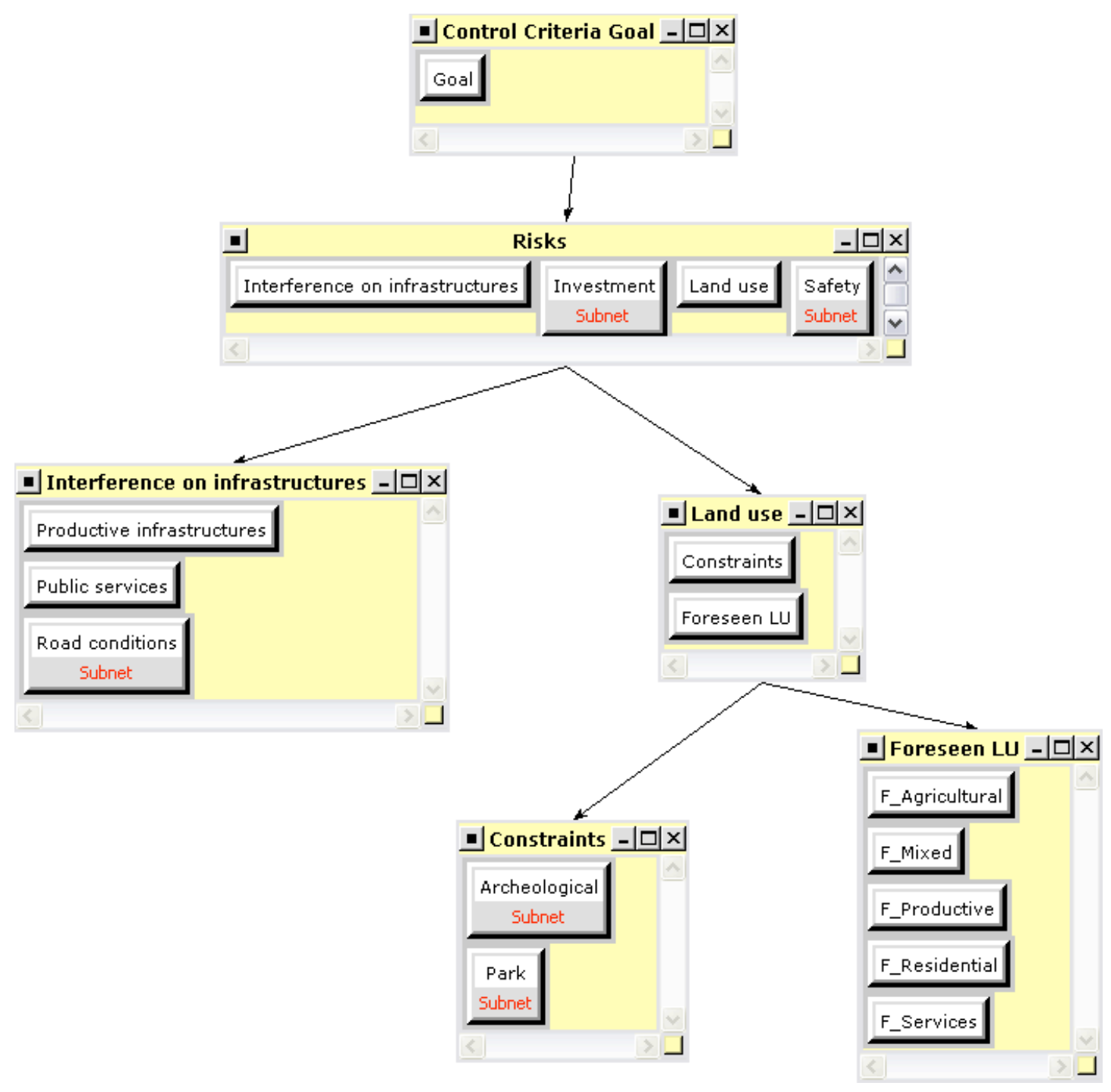

Figure 2. Risks hierarchical structure.

A subnet was created only for the most relevant criteria obtained with the AHP structure. Criteria whose weight did not reach a threshold of $2.9 \%$ were considered little significant, thus focusing the attention on the remaining 11 criteria, representing approximately $70 \%$ of the whole weight in the final decision. Some of these were considered more than once, in a short- and long-term perspective.

Figure 3 shows the weights of all the 49 criteria according to the AHP structure. Elements characterized by weights higher than the given threshold as reported in boldface. Figure 4, instead, reports the same criteria classified according to BOCR merits. 


\begin{tabular}{|c|c|c|c|c|c|}
\hline \multicolumn{4}{|c|}{ Investment $(0.1200)$} & Investment & 0,1200 \\
\hline \multirow{6}{*}{ Transportation efficiency $(0.3300)$} & & & & Safety & 0,0558 \\
\hline & \multirow{3}{*}{\multicolumn{3}{|c|}{ Competitiveness $(0.1279)$}} & Freight terminal & 0,0212 \\
\hline & & & & Regional transports & 0,0093 \\
\hline & & & & Tracks seili & 0,0973 \\
\hline & \multirow{2}{*}{\multicolumn{3}{|c|}{ Operations (0.1464) }} & Flexibility & 0,0732 \\
\hline & & & & Level of service & 0,0732 \\
\hline \multirow{34}{*}{ Territorial impact $(0.4000)$} & \multirow{18}{*}{ Environment $(0.1818)$} & \multirow{6}{*}{ Hydrogeological (0.0030) } & \multirow{3}{*}{ Hydric environment ( 0.0015$)$} & $\begin{array}{l}\text { Hydrogeology } \\
\text { Minor hydrogranow..... }\end{array}$ & 0,0005 \\
\hline & & & & $\begin{array}{l}\text { Minor hydrography. } \\
\text { Main hydrography. }\end{array}$ & $\begin{array}{l}0,0001 \\
0,0005\end{array}$ \\
\hline & & & & Secondary hydrography. & 0,0003 \\
\hline & & & \multirow{3}{*}{ Geomorphology (0.0015) } & A & 0,0008 \\
\hline & & & & B & 0,0004 \\
\hline & & & & C... & 0,0002 \\
\hline & & \multirow{6}{*}{ Natural env. $(0.0470)$} & \multirow{4}{*}{ Ecosystems (0.0141) } & Main corridors & 0,0078 \\
\hline & & & & Minor corridors & 0,0037 \\
\hline & & & & Ecosystems & 0,0008 \\
\hline & & & & Bushes & 0,0018 \\
\hline & & & \multirow[b]{2}{*}{ Vegetation (0.0329) } & Degraded autochthonous & 0,0132 \\
\hline & & & & Simplified autochthonous & 0,0198 \\
\hline & & \multirow{2}{*}{\multicolumn{2}{|c|}{ Landscape $(0.0189)$}} & Second-level. & 0,0113 \\
\hline & & & & Third-level & 0,0076 \\
\hline & & \multirow{4}{*}{ Noise and vibrations (0.1129) } & \multirow{2}{*}{ Noise $(0.0565)$} & $\mathrm{N}$ Residential & 0,0452 \\
\hline & & & & Sensitive receptors & 0,0113 \\
\hline & & & \multirow{2}{*}{ Vibrations (0.0565) } & Productive & 0,0226 \\
\hline & & & & V Residential & 0,0339 \\
\hline & \multirow{4}{*}{\multicolumn{3}{|c|}{ Historical patrimony (0.0364) }} & Churches & 0,0147 \\
\hline & & & & Historical buildings & 0,0085 \\
\hline & & & & Archeological sites & 0,0048 \\
\hline & & & & Vilias & 0,0085 \\
\hline & \multirow{12}{*}{ Land use (0.1818) } & \multirow{5}{*}{\multicolumn{2}{|c|}{ Current land use (0.0427) }} & C Agricultural & 0,0069 \\
\hline & & & & C Mixed & 0,0043 \\
\hline & & & & c Productive & 0,0026 \\
\hline & & & & C Residentiall & 0,0181 \\
\hline & & & & C services & 0,0108 \\
\hline & & \multirow{5}{*}{\multicolumn{2}{|c|}{ Foreseen land use $(0.0267)$}} & F Agricultural & 0,0043 \\
\hline & & & & F Mixed & 0,0027 \\
\hline & & & & F productive & 0,0016 \\
\hline & & & & F Residential & 0,0113 \\
\hline & & & & F Services & 0,0068 \\
\hline & & \multirow{2}{*}{\multicolumn{2}{|c|}{ Constraints (0.1123) }} & Park & 0,0786 \\
\hline & & & & Archeological sites & 0,0337 \\
\hline \multirow{7}{*}{ Project and realization $(0.1500)$} & & & & Bullding difficulties & 0,0165 \\
\hline & & Prolect constraints 10.075 & & Inert waste & 0,0078 \\
\hline & & Project constraints (0.0/3 & & Time iimits & 0,0214 \\
\hline & & & & Building constraints & 0,0292 \\
\hline & & & & Productive infrastructures & 0,0082 \\
\hline & & nterference on infrastructures & $(0.0750)$ & Public services & 0,0375 \\
\hline & & & & Road conditions & 0,0292 \\
\hline
\end{tabular}

Figure 3. Weights of criteria according to the AHP structure.

Decision subnets consider the relative influence among the four decision makers (the Italian railway infrastructure manager, the Regional government, the Province and the Municipality of Turin), the possible stakeholders influenced by the decision (Railway operating companies, Commuters, Pressure groups such as environmentalists, the Turin population, the Industrial world and the Logistics operators) and the four alternatives. Of course, not all of these actors -Decision makers and stakeholders- intervene in all of the subnets. For example the subnet regarding the criterion "Impact on the Road Conditions" included in the Risks hierarchy is shown in Figure 5. In this case, the Railway infrastructure manager for Italy has no relevance in the problem, as well as only two of the six stakeholders were considered with respect to this criterion. The four alternatives, on the contrary, are present in all subnets.

In sum, the intervention of different actors, the reciprocal influences among them and the performances of the alternatives differ in each subnet, reflecting the change in the point of view of the analysis with respect to the control criterion taken into consideration. 
G. Longo, E. Padoano, P. Rosato, S. Strami/ Considerations on the application of AHP/ANP methodologies to decisions concerning a railway infrastructure

\begin{tabular}{|c|c|c|c|c|}
\hline \multirow{5}{*}{ Benefits (0.1933) } & \multirow{3}{*}{\multicolumn{2}{|c|}{ Opportunities }} & \multicolumn{2}{|r|}{ Tracks sell } \\
\hline & & & \multirow{2}{*}{ Operations } & Flexibility \\
\hline & & & & Level of service \\
\hline & \multirow{2}{*}{\multicolumn{2}{|c|}{ Competitiveness }} & & Regional transport \\
\hline & & & & Freight terminal \\
\hline \multirow{3}{*}{ Opportunities $(0.2867)$} & & & & Tracks sell \\
\hline & \multirow{2}{*}{\multicolumn{3}{|c|}{ Operations }} & Flexibility \\
\hline & & & & Level of service \\
\hline \multirow{25}{*}{ Costs $(0.2700)$} & Investment & & & Investment \\
\hline & \multirow{14}{*}{ Environment } & \multirow{6}{*}{ Hydrogeological } & \multirow{3}{*}{ Hydric environment } & Hydrogeology \\
\hline & & & & Minor hydrography \\
\hline & & & & $\begin{array}{l}\text { Main hydrography } \\
\text { Secondary hydrography }\end{array}$ \\
\hline & & & \multirow{3}{*}{ Geomorphology } & A \\
\hline & & & & $\mathrm{B}$ \\
\hline & & & & $\frac{\mathrm{C}}{\text { Main corridors }}$ \\
\hline & & \multirow{4}{*}{ Natural env. } & \multirow{3}{*}{ Ecosystems } & Minor corridors \\
\hline & & & & Ecosystems \\
\hline & & & & Bushes \\
\hline & & & Vegetation & $\begin{array}{l}\text { Deqraded autochthonous } \\
\text { Simplified autochthonous }\end{array}$ \\
\hline & & \multicolumn{2}{|c|}{ Landscape } & $\begin{array}{l}\text { Second-level } \\
\text { Third-level }\end{array}$ \\
\hline & & \multirow{3}{*}{ Noise and vibrations } & & N Residential \\
\hline & & & Noise & Sensitive receptors \\
\hline & & & Vibrations & $\frac{\text { Productive }}{\text { V_Residential }}$ \\
\hline & \multirow{3}{*}{\multicolumn{3}{|c|}{ Historical patrimony }} & Churches \\
\hline & & & & Historical buildings \\
\hline & & & & $\begin{array}{l}\text { Archeological sites } \\
\text { Villas }\end{array}$ \\
\hline & \multirow{4}{*}{\multicolumn{3}{|c|}{ Land use }} & C Aqricultural \\
\hline & & & & C Mixed \\
\hline & & & & C Productive \\
\hline & & & & C Services \\
\hline & \multirow{3}{*}{\multicolumn{3}{|c|}{ Project constraints }} & Building difficulties \\
\hline & & & & Inert waste \\
\hline & & & & Time limits \\
\hline \multirow{11}{*}{ Risks $(0.2500)$} & \multirow{7}{*}{\multicolumn{2}{|c|}{ Foreseen land use }} & & F Aqricultural \\
\hline & & & & F Mixed \\
\hline & & & Foreseen land use & F Productive \\
\hline & & & & F Residential \\
\hline & & & & F Services \\
\hline & & & Constraints & Park \\
\hline & \multirow{3}{*}{\multicolumn{3}{|c|}{ Interference on infrastructures }} & $\begin{array}{l}\text { Archeological sites } \\
\text { Productive infrastructures }\end{array}$ \\
\hline & & & & Public services \\
\hline & & & & Road conditions \\
\hline & Investment & & & Investment \\
\hline & Safety & & & Safety \\
\hline
\end{tabular}

Figure 4. Criteria classified according to BOCR merits.

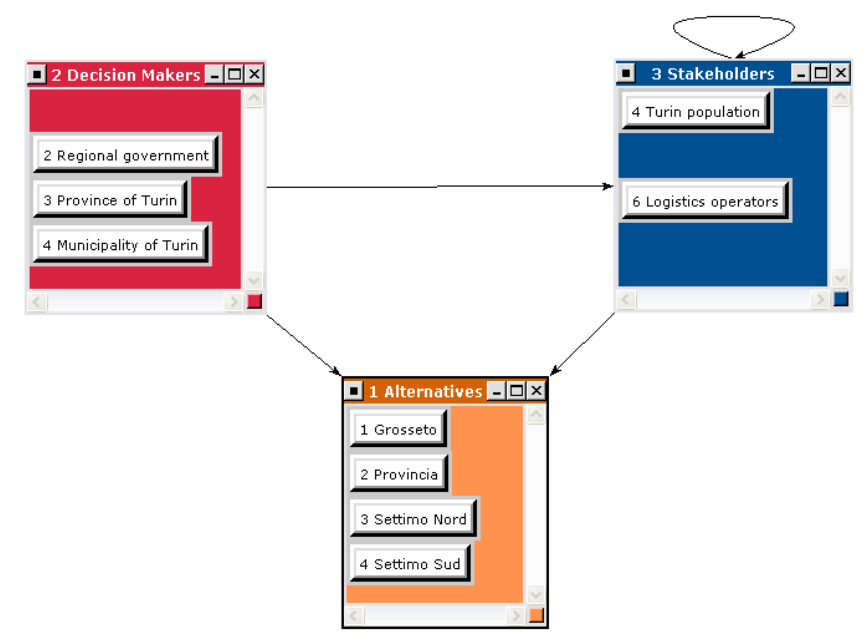

Figure 5. Subnet related to the criterion "Impact on the road conditions".

As an example, Figure 6 reports the limit supermatrix referred to the criterion "Road conditions" belonging to "Risks" merit class. 


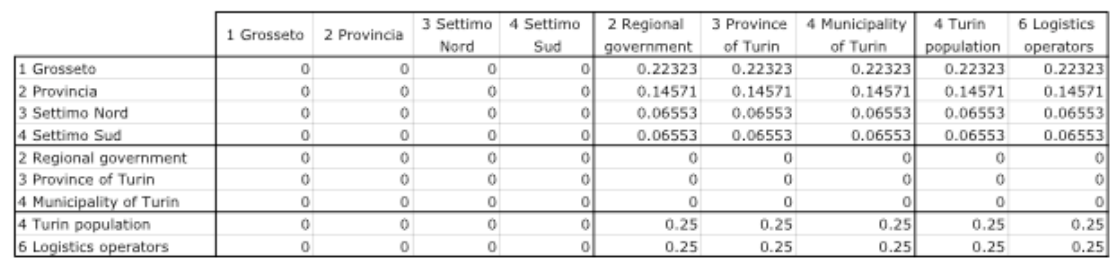

Figure 6. Risks/Road Conditions limit matrix.

The general structure of the model is presented in Figure 7. At the top level the main goal is presented ("Selection of the best project" for the considered case study). Secondly, the four strategic criteria leading to the decision are reported. Then the BOCR merits are shown, including only the considered control criteria. At the bottom, a generic example of subnet is included. Of course, specific subnets differ one from another as described before.

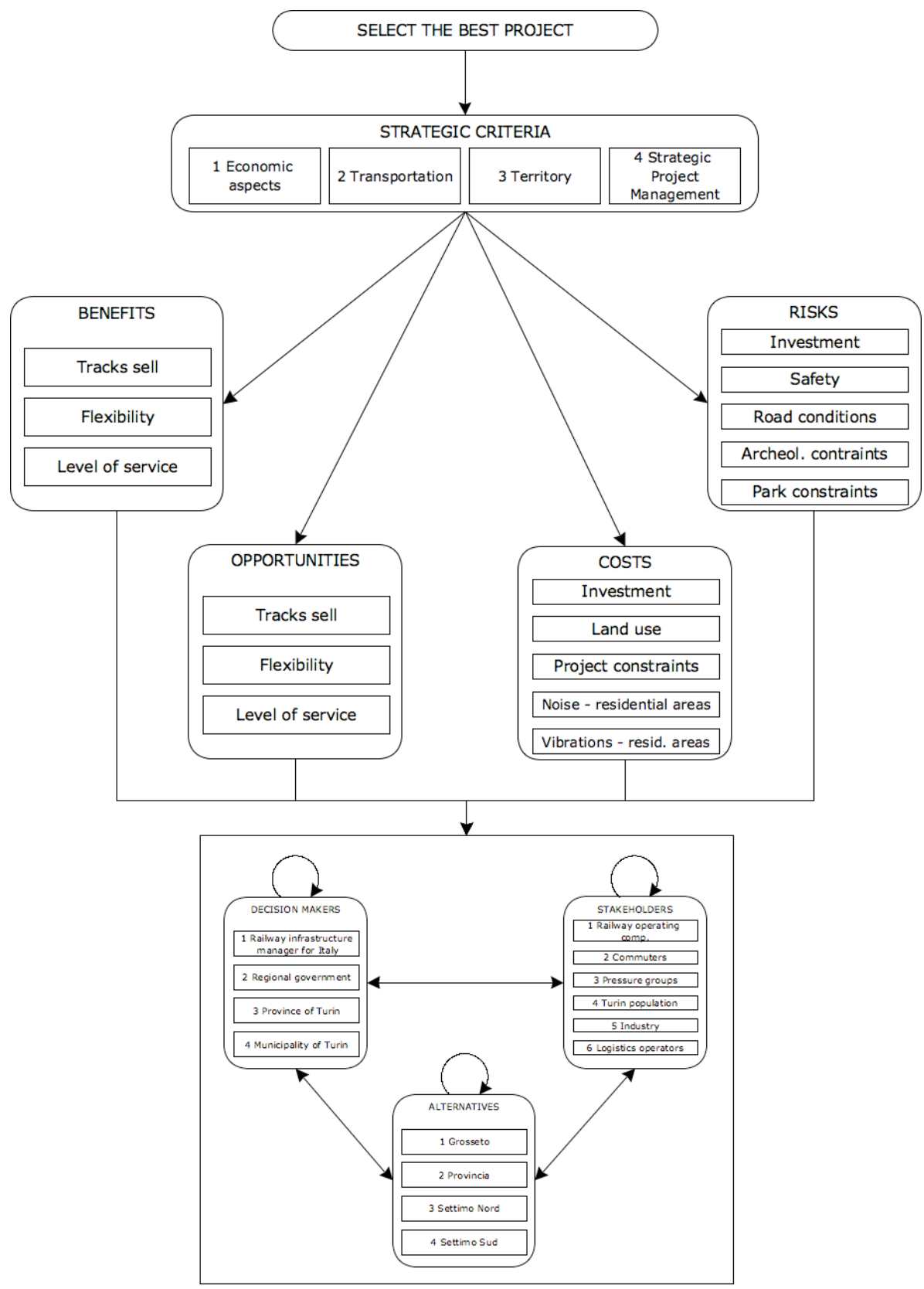

Figure 7. Comprehensive BOCR structure. 
Figures 8-11 report the ranking of the four alternatives with reference to the four merit classes respectively (Benefits, Opportunities, Costs and Risks). It should be noticed that the alternative "Grosseto" is the most important for the Benefits and also for Costs and Risks networks (therefore the most costly and risky). Moreover, the alternatives "Settimo Nord" and "Settimo Sud" seem to be indistinguishable in all the histograms. This can be explained considering the nature of the differences between them (only technical details), which is probably unperceived by the political decision makers.

\begin{tabular}{|l|l|l|l|l|}
\hline \multicolumn{1}{|c|}{ Name } & \multirow{2}{|c|}{ Graphic } & Ideals & Normals & Raw \\
\hline \hline 1 Grosseto & & 1.000000 & 0.286895 & 0.715112 \\
\hline \hline 2 Provincia & & 0.836545 & 0.240001 & 0.598223 \\
\hline 3 Settimo Nord & & 0.824526 & 0.236552 & 0.589628 \\
\hline 4 Settimo Sud & & 0.824526 & 0.236552 & 0.589628 \\
\hline
\end{tabular}

Figure 8. Rankings of the Benefits network.

\begin{tabular}{|l|c|c|c||c|}
\hline \multicolumn{1}{|c|}{ Name } & Graphic & Ideals & Normals & Raw \\
\hline \hline 1 Grosseto & & 0.655077 & 0.198718 & 0.618288 \\
\hline \hline 2 Provincia & & 0.641460 & 0.194588 & 0.605435 \\
\hline 3 Settimo Nord & & 1.000000 & 0.303351 & 0.943840 \\
\hline \hline 4 Settimo Sud & & 0.999971 & 0.303343 & 0.943813 \\
\hline
\end{tabular}

Figure 9. Rankings of the Opportunities network.

\begin{tabular}{|l|l|l|l||c|}
\hline \multicolumn{1}{|c|}{ Name } & Graphic & Ideals & Normals & Raw \\
\hline \hline 1 Grosseto & & 1.000000 & 0.396909 & 1.000000 \\
\hline \hline 2 Provincia & & 0.769334 & 0.305355 & 0.769334 \\
\hline 3 Settimo Nord & & 0.375067 & 0.148867 & 0.375067 \\
\hline 4 Settimo Sud & & 0.375070 & 0.148868 & 0.375070 \\
\hline
\end{tabular}

Figure 10. Rankings of the Costs network.

\begin{tabular}{|l|c|c|c||c|}
\hline \multicolumn{1}{|c|}{ Name } & Graphic & Ideals & Normals & Raw \\
\hline \hline 1 Grosseto & & 1.000000 & 0.332865 & 0.854135 \\
\hline \hline 2 Provincia & & 0.621792 & 0.206973 & 0.531094 \\
\hline 3 Settimo Nord & & 0.691214 & 0.230081 & 0.590390 \\
\hline \hline 4 Settimo Sud & & 0.691214 & 0.230081 & 0.590390 \\
\hline
\end{tabular}

Figure 11. Rankings of the Risks network

Ratings were calculated for the four merit classes by assigning a judgment to the most important alternative (in Benefits, Opportunities, Costs and Risks respectively) with reference to each strategic criterion, as reported in Figure 12. In each case analysts were asked a question such as the following: "In terms of Impact on the territory, what would be the level of (beneficial) outcome for the most important alternative in the Benefits merit class?". Numerically, a 2-10 scale was adopted - "Very low" corresponds to 0.2, "Low" $=0.4, \ldots$, "Very High" $=1.0$. 


\begin{tabular}{l|l|c|c|c|c|} 
& Priorities & $\begin{array}{l}1 \text { Economic crit. } \\
0.300000\end{array}$ & $\begin{array}{l}4 \text { Strategic project } \\
0.100000\end{array}$ & $\begin{array}{l}3 \text { Territory } \\
0.350000\end{array}$ & $\begin{array}{l}2 \text { Transportation } \\
0.250000\end{array}$ \\
\hline Benefits & 0.193333 & Medium & Very low & High & Low \\
\hline Dpportunities & 0.286667 & Very high & Very high & Medium & Very high \\
\hline Costs & 0.270000 & Very high & Very high & Medium & High \\
\hline Risks & 0.250000 & High & High & High & Medium \\
\hline
\end{tabular}

Figure 12. Ratings of the four merits.

The results of the synthesis of the whole model, obtained with the multiplicative formula $\left(B^{*} O / C^{*} R\right.$ ) show a remarkable prevalence of the two "Settimo" options, which seem to perform extremely better than "Provincia" and "Grosseto" (Figure 13). The ranking actually corresponds to what had been obtained with the AHP model and confirmed via ANP. Figure 14 reports the results offered by the additive (negative) formula

$$
b B+o O-c C-r R
$$

which underline the low interest in investing in alternatives such as "Grosseto" and "Provincia". Factors $b, \mathrm{o}, \mathrm{c}$ and $\mathrm{r}$ correspond to the "Priorities" of the different merit classes as reported in Figure 12. Their high performances as far as only Benefits are concerned may, effectively, induce local governments to propose them, but the heavy drawbacks in terms of Costs and Risks seem to make them far less attractive.

\begin{tabular}{|l|l|l|l||c|}
\hline \multicolumn{1}{|c|}{ Name } & \multirow{2}{|c|}{ Graphic } & Ideals & Normals & Raw \\
\hline \hline 1 Grosseto & & 0.205973 & 0.080501 & 0.517653 \\
\hline \hline 2 Provincia & & 0.352708 & 0.137850 & 0.886430 \\
\hline 3 Settimo Nord & & 1.000000 & 0.390832 & 2.513208 \\
\hline 4 Settimo Sud & & 0.999965 & 0.390818 & 2.513121 \\
\hline \hline
\end{tabular}

Figure 13. Results obtained with the multiplicative formula.

\begin{tabular}{|l|c|c|c|c|}
\hline \multicolumn{1}{|c|}{ Name } & \multirow{2}{*}{ Graphic } & Ideals & Normals & Raw \\
\hline \hline 1 Grosseto & & -1.000000 & -0.342442 & -0.168036 \\
\hline \hline 2 Provincia & & -0.305168 & -0.104502 & -0.051279 \\
\hline 3 Settimo Nord & & 0.807544 & 0.276537 & 0.135697 \\
\hline 4 Settimo Sud & & 0.807494 & 0.276520 & 0.135688 \\
\hline
\end{tabular}

Figure 14. Results obtained with the additive (negative) formula.

The BOCR model surely helped in understanding the different points of view that mixed together in the discussion of the problem. It made it possible, indeed, to underline how the local authorities, who introduced the urban solutions "Grosseto" and "Provincia", were not aware of the complexity of the question and, in particular, disregarded the negative outcomes of the alternatives proposed.

\section{Conclusions}

The BOCR scheme, adopted in the case study, proved to be very effective as a support tool for analyzing the different aspects of the decision process in which several actors were involved. The evaluation stage was carried out by a group of analysts and experts. For such participants, the 
opportunity to focus the attention on a network of decision makers, stakeholders and alternatives specifically designed for each criterion, made it possible to highlight the relations among the elements and therefore to appreciate the different perspectives assumed by the parties involved in the decision. The results of the study here discussed and those obtained in the preceding part of the research, bring forth some observations regarding practical issues of AHP and ANP implementation.

AHP resulted simple and efficient for problem structuring and for the analysis and synthesis of the performances of alternatives in a goal-oriented perspective. It proved to be comprehensible by the actors involved in the decision making process who felt comfortable with the method and with the results it could produce. However, the problem issue made it evident that the AHP framework is too rigid when priorities are mutually dependent and it does not allow to describe in detail the point of view of the decision makers.

ANP allowed to better represent the preference structure of decision makers and, in general, the problem situation because of its intrinsic systemic framework, but it was quite more complex to employ. The approach needs to investigate more accurately the problem issue and the stakeholders' system of preferences. In fact, an effective information exchange between the analyst and the decision maker depends on a clear comprehension of the structure of the model by the key decision makers that should be deeply involved in every stage of model building. This fact makes more problematic the practical application of the ANP approach, at least for public decisions in Italy.

\section{REFERENCES}

De Brucker, K., Alain Verbeke, A., \& Macharis, C. (2004). The applicability of multicriteria-analysis to the evaluation of intelligent transport systems (ITS). Research in Transportation Economics, 8, $151-179$.

Forman, E.H., \& Gass, S.I. (2001). The Analytic Hierarchy Process: an exposition. Operations Research, 49, 469-486.

Gerçek, H., Karpak, B., \& Kilinçaslan, T. (2004). A multiple criteria approach for the evaluation of the rail transit networks in Istanbul. Transportation, 31, 203-228.

Longo, G., Padoano, E., Rosato, P. \& Strami, S. (2008). AHP vs. ANP for the planning of a freight railway line: evidences from the Turin case study. Presented at the International Conference "Transportation decision making: issues, tools, models and case studies", Venice (Italy), $13^{\text {th }}-14^{\text {th }}$ November.

Meade, L., \& Sarkis, J. (1998), Strategic analysis of logistics and supply chain management systems using the analytic network process. Transportation Research Part E, 34, 201-215.

Mingers, J., \& Rosenhead, J. (2001). Rational analysis for a problematic world revisited: problem structuring methods for complexity, uncertainty and conflict. Chichester, UK: John Wiley \& Sons.

Piantanakulchai, M. (2005). Analytic Network Process model for highway corridor planning. Proceedings of ISAHP 2005, Honolulu, Hawaii.

Rabbani, S.J.R., \& Rabbani, S. R. (1996). Transportation Decisions with the Analytic Hierarchy Process. Civil Engineering Department, Federal University of Paraiba, Brasil.

Saaty, T.L. (1996). Decision making in complex environments: the Analytic Network Process for decision making with dependence and feedback. Pittsburgh, PA: RWS Publications. 
Saaty, T.L. (1999). Fundamentals of the Analytic Network Process. Proceedings of ISAHP 1999, Kobe, Japan.

Saaty, T.L. (2001). Decision making with the Analytic Network Process (ANP) and its "SuperDecisions" software: the National Missile Defense (NMD) example. Proceedings of ISAHP 2001, Berne, Switzerland.

Saaty, T.L. (2005). Theory and Applications of the Analytic Network Process: Decision Making with Benefits, Opportunities, Costs, and Risks. Pittsburgh, PA: RWS Publications.

Saaty, T.L. (2008). Decision Making for Leaders: the Analytic Hierarchy Process for decisions in a complex world, 5th edition. Pittsburgh, PA: RWS Publications.

Shang, J. S., Tjader, Y., \& Ding, Y. (2004). A unified framework for multicriteria evaluation of transportation projects. IEEE Transactions on Engineering Management, 51, 300-313.

Simon, H.A. (1957). Models of man. New York: John Wiley \& Sons.

Tsamboulas, D., \& Mikroudis, G. (2000). EFECT: evaluation framework of environmental impacts and costs of transport initiatives. Transportation Research Part D, 5, 283-303.

Tudela, A., Akiki, N., \& Cisternas, R. (2006). Comparing the output of cost benefit and multi-criteria analysis: an application to urban transport investments. Transportation Research Part A, 40, 414-423.

Yedla, S., \& Shrestha, R.M. (2003). Multi-criteria approach for the selection of alternative options for environmentally sustainable transport system in Delhi. Transportation Research Part A, 37, 717-729. 